\title{
Connectivity of larval cod in the transition area between North Sea and Baltic Sea and potential implications for fisheries management
}

\author{
Huwer, Bastian; Hinrichsen, H.-H.; Hüssy, Karin; Eero, Margit
}

Published in:

ICES Journal of Marine Science

Link to article, DOI:

10.1093/icesjms/fsw043

Publication date:

2016

Document Version

Publisher's PDF, also known as Version of record

Link back to DTU Orbit

Citation (APA):

Huwer, B., Hinrichsen, H-H., Hüssy, K., \& Eero, M. (2016). Connectivity of larval cod in the transition area between North Sea and Baltic Sea and potential implications for fisheries management. ICES Journal of Marine Science, 73(7), 1815-1824. https://doi.org/10.1093/icesjms/fsw043

\section{General rights}

Copyright and moral rights for the publications made accessible in the public portal are retained by the authors and/or other copyright owners and it is a condition of accessing publications that users recognise and abide by the legal requirements associated with these rights.

- Users may download and print one copy of any publication from the public portal for the purpose of private study or research.

- You may not further distribute the material or use it for any profit-making activity or commercial gain

- You may freely distribute the URL identifying the publication in the public portal 


\title{
ICES Journal of Marine Science
}

\section{Original Article}

\section{Connectivity of larval cod in the transition area between North Sea and Baltic Sea and potential implications for fisheries management}

\author{
B. Huwer ${ }^{1 *}$, H.-H. Hinrichsen ${ }^{2}$, K. Hüssy', and M. Eero ${ }^{1}$ \\ ${ }^{1}$ National Institute of Aquatic Resources, Technical University of Denmark, Charlottenlund Castle, Jeegersborg Allee 1, Charlottenlund DK-2920, \\ Denmark \\ ${ }^{2}$ GEOMAR Helmholtz Centre for Ocean Research Kiel, Düsternbrooker Weg 20, Kiel 24105, Germany
}

*Corresponding author: e-mail: bhu@aqua.dtu.dk

Huwer, B., Hinrichsen, H.-H., Hüssy, K., and Eero, M. Connectivity of larval cod in the transition area between North Sea and Baltic Sea and potential implications for fisheries management. - ICES Journal of Marine Science, 73: 1815- 1824.

Received 17 August 2015; accepted 7 February 2016.

Connectivity of pelagic, early life stages via transport by ocean currents may affect survival chances of offspring, recruitment success, and mixing of stocks across management units. Based on drift model studies, transport patterns of particles representing exogenously feeding cod larvae in the transition area between North Sea and Baltic were investigated to (i) determine long-term trends and variability in advective transport of larvae from spawning grounds to juvenile nursery areas, (ii) estimate the degree of exchange between different management areas, and (iii) compare the results with spatial distributions of juvenile cod. The transport of particles showed considerable intra- and interannual variability, but also some general patterns of retention within and dispersion to different management areas. Good spatial overlap of particle end positions, representing potential juvenile settlement areas, with observed distributions of juveniles in bottom trawl surveys suggests that the drift simulations provide reasonable estimates of early life stage connectivity between cod populations in the investigated areas. High exchange rates of particles between management areas of up to ca. $70 \%$ suggest that cod populations in the investigated areas are demographically correlated. Results are discussed in relation to their relevance for stock structure, fish stock assessment, and management.

Keywords: connectivity, early life stages, fisheries management, juvenile nursery areas, spatial management, stock structure.

\section{Introduction}

The exchange of individuals among populations and habitats is an important process from an ecological perspective, affecting, e.g. species distribution ranges, the demographic and genetic structure of populations, population dynamics, density-dependent processes and species interactions (Roughgarden et al., 1988; Gaines and Lafferty, 1995; Gaylord and Gaines, 2000; Grosberg and Cunningham, 2001; Hixon et al., 2002). In the marine world, connectivity of pelagic early life stages via ocean currents is of particular interest (e.g. Cowen and Sponaugle, 2009), as retention in or transport to favourable or unfavourable habitats may lead to variability in survival chances and eventually in recruitment success (Sinclair, 1988; Baumann et al., 2006; Huwer et al., 2014). In commercially important marine fish stocks which are annually assessed to estimate stock size and status and to inform about resulting fishing opportunities, the exchange of individuals between different management units is particularly important (Selkoe et al., 2008; Reiss et al., 2009; Eero et al., 2014).
According to Gulland (1983) a 'stock' is assumed to be a discrete group of fish which show little mixing with adjacent groups and which have the same growth and mortality parameters across a particular geographical area. If large numbers of individuals are moving across boundaries of management units, either by active migration or by passive transport, this may lead to erroneous assumptions about stock-recruitment relationships, growth and mortality parameters needed in stock assessment and, due to variable fishing effort between management units, to overexploitation of certain stocks or stock units (Heath et al., 2013; Eero et al., 2014). Thus, management strategies will benefit from increased understanding of movement patterns in space and time and linkages among populations by exchange of eggs, larvae, juveniles, or adults, i.e. population connectivity (Palumbi, 2004).

Many marine fish stocks are managed in large areas, which often have limited connection to management areas of neighbouring stocks, e.g. the Arcto-Norwegian cod north of Norway and the 


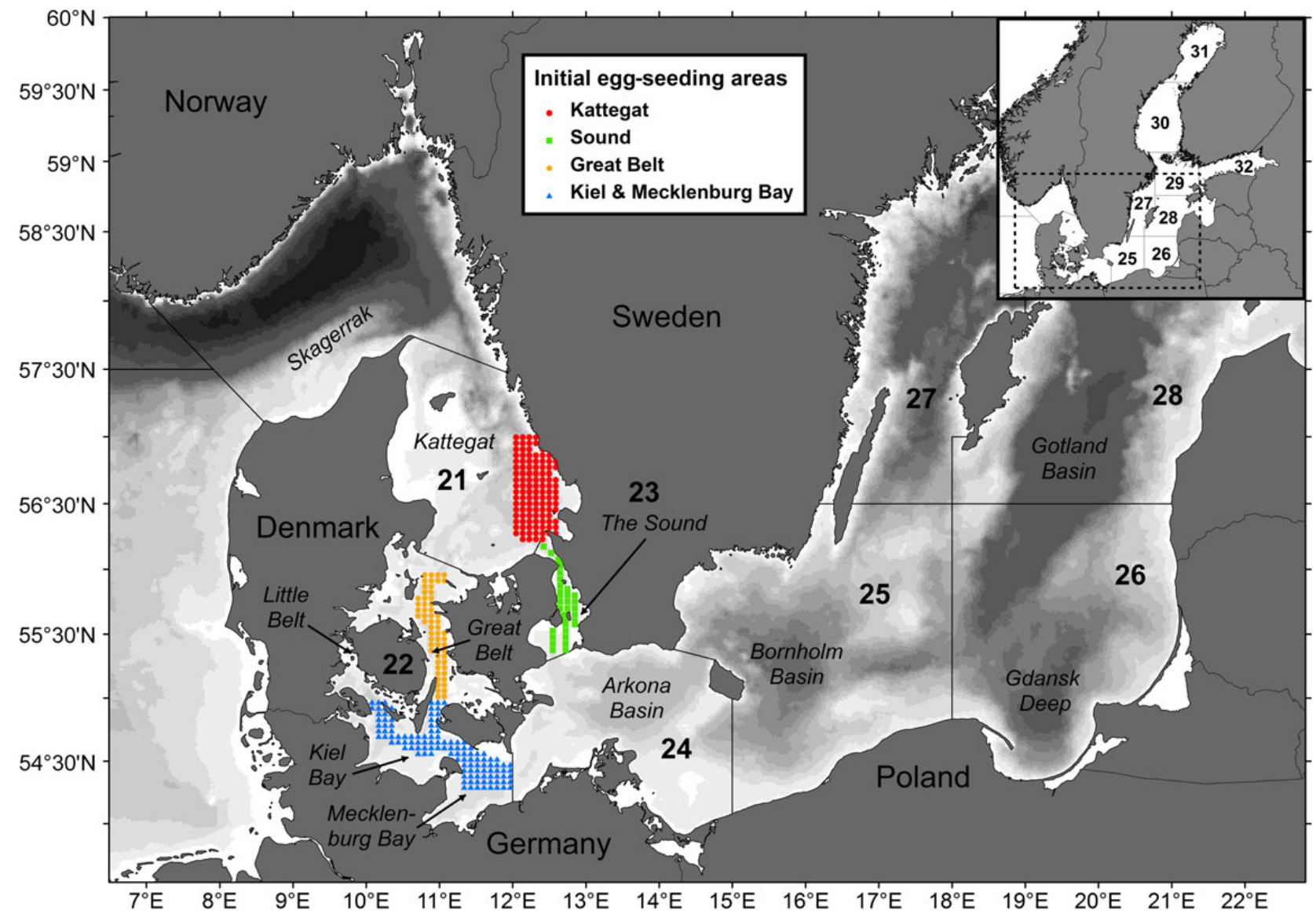

Figure 1. Overview of the study area. Symbols represent areas of historical spawning activity and grid of cod egg particle release positions in the Kattegat, the Sound, the Great Belt, and the Kiel \& Mecklenburg Bay. Numbers indicate ICES Subdivisions. For a colour representation of the figure, it is referred to the online version. This figure is available in black and white in print and in colour at ICES Journal of Marine Science online.

northern cod in the Southern Labrador and eastern Newfoundland area (ICES, 2005), or Baltic sprat which is managed as a single unit in ICES Subdivisions 22-32 (ICES, 2015a) with only a very small border to one adjacent management unit in the area of the Belt Sea (see Figure 1).

In contrast, in the transition area between North Sea and Baltic Sea, there are four cod stocks which are managed in separate, relatively small management units, which are in close vicinity to each other (Figure 1): (i) Skagerrak (together with North Sea), (ii) Kattegat in ICES SD 21, (iii) western Baltic cod in SDs 22-24, and (iv) eastern Baltic cod in SDs 25-32 (see Figure 1; ICES, 2015a,b).

The spawning grounds of cod in these areas are generally well described and their spatial distribution seems to be rather stable over the years (see Hüssy, 2011; Hüssy et al., 2012 and references therein). Although a number of relevant processes for recruitment success of cod in the western Baltic and the Kattegat have been identified, recruitment dynamics and potential exchange of recruits between the different spawning and management areas are poorly known (Hüssy, 2011) and it is generally recognized that the cod stock structure and the borders of distribution areas of populations inhabiting the transition area from the North Sea to the Baltic are unclear (Nielsen et al., 2005; Svedäng and Svenson, 2006). Cod populations in this region apparently consist of a mixture of resident and migratory stocks (Svedäng and Svenson, 2006; Svedäng et al., 2007, 2010a; Hüssy, 2011). Consequently, considerable mixing of stocks in this region may be anticipated as a result of both migrations of adult fish as well as drift of early life stages (Hüssy, 2011).

Despite this evidence of connectivity between areas, the standard stock assessments for cod in the Baltic and North Sea region have only recently begun to consider mixing between management areas, e.g. for eastern and western Baltic cod stocks mixing in SD 24 (Hüssy et al., 2015; ICES, 2015a,c). Stock mixing in the areas from Skagerrak and Kattegat over the Belt Sea to the Arkona basin (ICES SD's 20-24, see Figure 1) is not taken into account. From a management perspective, it must be emphasized to gain a better understanding of connectivity in this region at different life history stages to elucidate the resulting recruitment and stock dynamics as well as the recovery potential and appropriate management measures for the cod stocks.

In previous studies, we have assessed the importance of variability in environmental conditions for egg survival within different spawning grounds of cod stocks in the North Sea-Baltic Sea transition area (Hüssy et al., 2012) as well as the advective transport and the variability in environmentally mediated survival of eggs and yolk-sac larvae along drift routes in relation to both spatial and temporal dynamics (Hinrichsen et al., 2012). The aim of the present study was to go a step further in the life cycle by exploring the fate of offspring during the exogenously feeding larval stage. We utilized a hydrodynamic model to simulate the drift of exogenously feeding cod larvae which were originally released on different spawning 
Table 1. Sizes of spawning grounds, larval hatching grounds and spatial overlap of hatching grounds with spawning grounds for early, middle, and late western Baltic cod spawners (all values are in $\mathrm{km}^{2}$ ).

\begin{tabular}{|c|c|c|c|c|c|c|c|c|c|c|c|c|c|c|c|c|}
\hline \multirow[b]{3}{*}{ Area } & \multirow[b]{3}{*}{ Spawning ground size } & \multirow{2}{*}{\multicolumn{3}{|c|}{$\begin{array}{l}\text { Hatching ground } \\
\text { size }\end{array}$}} & \multicolumn{12}{|c|}{ Spatial overlap between hatching grounds and spawning grounds } \\
\hline & & & & & \multicolumn{3}{|c|}{ Kattegat } & \multicolumn{3}{|c|}{ Øresund } & \multicolumn{3}{|c|}{ Great Belt } & \multicolumn{3}{|c|}{ Western Baltic } \\
\hline & & Early & Mid & Late & Early & Mid & Late & Early & Mid & Late & Early & Mid & Late & Early & Mid & Late \\
\hline Kattegat & 2825 & 6675 & 6675 & 5700 & 450 & 100 & 900 & 1125 & 300 & 1500 & 0 & 0 & 0 & 0 & 0 & 0 \\
\hline$\varnothing$ resund & 850 & 6475 & 6825 & 3775 & 0 & 0 & 0 & 25 & 0 & 75 & 0 & 0 & 0 & 0 & 0 & 0 \\
\hline Great Belt & 1440 & 8225 & 9225 & 5125 & 0 & 0 & 0 & 0 & 0 & 0 & 900 & 885 & 900 & 300 & 830 & 325 \\
\hline Western Baltic & 3085 & 6325 & 7750 & 5425 & 0 & 0 & 0 & 0 & 0 & 0 & 80 & 0 & 55 & 1125 & 1290 & 950 \\
\hline
\end{tabular}

grounds in the western Baltic and the Kattegat. The objectives of the study were to (i) determine long-term trends and variability in advective transport of larvae from spawning grounds to juvenile nursery areas; (ii) estimate the degree of exchange between the management areas of eastern and western Baltic, Kattegat, and North Sea; and (iii) compare the results with spatial distributions of juvenile cod. The results are discussed in the light of their potential influence on genetic diversity as well as their relevance for stock assessment and management in the transition area between the North Sea and the Baltic.

\section{Material and methods Identification of larval release areas}

In previous studies, major spawning grounds of cod in the transition area between North Sea and Baltic (Figure 1) were identified to be located in the Kattegat, the Sound, the Little and Great Belt, Kiel Bay, the Fehmarn Belt, and to a limited degree in Mecklenburg Bay (Hüssy, 2011; Hüssy et al., 2012 and references therein). Based on spatio-temporal distributions of drifting particles representing yolk-sac larvae of western Baltic cod at the end of the endogenous feeding period obtained from a previous modelling study (Hinrichsen et al., 2012), spatial distributions of seeding areas for particles representing feeding larvae were identified. This was done by calculation of dispersal kernels (Edwards et al., 2007) from principal component analysis (Hinrichsen et al., 2012) for particles which were initially released as spawned eggs at each of the specific spawning grounds (Figure 1). Based on the duration of the spawning season from December to May, particles were seeded at the centre of the grid cells every 10 days from December 11 to June 10, resulting in 19 different release dates throughout the spawning season. To account for seasonal variations, we chose different release areas of feeding larvae for the early (December-January), mid (February-March), and late (April-June) spawning season. As a second step, we used results from hydrodynamic model runs, combined with a drift model approach considering feeding larval cod as drifting particles, to hindcast long-term spatio-temporal distributions of these late larval stages.

\section{Hydrodynamic model}

The hydrodynamic model is based on the free surface Bryan-CoxSemtner model (Killworth et al., 1991) which is a special version of the Cox numerical ocean general circulation model (Bryan, 1969; Semtner, 1974; Cox, 1984). A detailed description of the equations and modifications made, necessary to adapt the model to the Baltic Sea can be found in Lehmann (1995) and Lehmann and Hinrichsen (2000). The model domain comprises the entire Baltic Sea. The horizontal resolution is $5 \mathrm{~km}$, with 60 vertical levels specified. The Baltic Sea model is driven by atmospheric data provided by the Swedish
Meteorological and Hydrological Institute (Norrköping, Sweden) and river run-off taken from a monthly mean run-off database (Bergstrøm and Carlsson, 1994). Physical properties simulated by the hydrodynamic model agree well with known circulation features and observed physical conditions in the Baltic (for further description, see Lehmann, 1995; Hinrichsen et al., 1997; Lehmann and Hinrichsen, 2000).

\section{Drift model}

The drift model tracks individual feeding larvae through space and time. To consider the seasonal variability of the environmental conditions in relation to its spatial and temporal variability, locations were extracted at the hydrodynamic model $5 \times 5 \mathrm{~km}$ grid within the estimated hatching areas. In the vertical domain, particles were released between 1.5 and $28.5 \mathrm{~m}$ depths at a $3 \mathrm{~m}$ depth interval (Hinrichsen et al., 2001). This range was chosen based on the only study of larval cod vertical distribution in the western Baltic Sea, where larvae were found in the depth range 0-30 m, with spatiotemporal differences in depths of highest densities (Westerberg, 1994). To estimate potential effects of vertical migration behaviour, a sensitivity analysis was performed by analysing the drift of particles for three different depth layers $(0-10,10-20$, and 20-30 m) separately. The spatio-temporal variability of habitat size of larval release areas is given in Table 1 . A total of 494 ( 26 years $\times 19$ release dates) drift model runs were performed. The larval particles were tracked for a duration of 90 days. The seeding positions were located in the four subregions representing the above defined larval release areas. Finally, to obtain some simple indications for the connectivity of the early life stages of the western Baltic cod stock, we calculated the spatial overlap between their spawning and hatching grounds in terms of sizes for commonly utilized areas.

\section{Model run}

Simulated three-dimensional velocity fields were extracted (at $1 \mathrm{~h}$ intervals) from the hydrodynamic model to develop a database for particle tracking. This dataset offers the possibility to derive Lagrangian drift routes by calculating the advection of "marked" water particles. Simulated drift routes were obtained from Eulerian flowfields using a Lagrangian particle-tracking technique. The threedimensional trajectories of the simulated particles were computed using a fourth-order Runge-Kutta scheme (Hinrichsen et al., 1997). The distribution of particles at the end of the 90 days drift duration, representing relative abundances of late larval/early juvenile stages, was recorded. The model runs addressed the question how many particles originating in the different release areas were retained and how many were transported into adjacent areas. To quantify retention within and dispersal to adjacent areas, we produced time series of average proportions of particle end positions for the four spawning 
areas for the entire season as well as seasonally resolved for early, mid, and late season for each year from 1979 to 2004 . Area-specific averages and standard deviations of proportions of final drift destinations for all years from 1979 to 2004 were determined for the four release areas in early, mid, late, and total spawning season.

\section{Comparison of particle end positions with spatial distribution of juvenile cod}

To test the results from the drift modelling, we compared maps of average particle end positions per ICES quarter square, representing potential juvenile settlement areas, with the observed spatial distribution of juvenile cod. To that end, catch per unit effort (cpue) data of 0 -group cod from regularly conducted standard bottom trawl surveys in the area were downloaded from the ICES trawl database (ICES Database of Trawl Surveys, 2015, International Bottom Trawl Survey (IBTS) and Baltic International Trawl Survey, ICES, Copenhagen). For more details, see Supplementary Material.

\section{Results}

In the following sections, results concerning the extent of larval release areas and particle end positions are mainly described for the entire spawning season, while their seasonal variations are presented in detail in Supplementary Material.

\section{Release areas of feeding larvae}

Seeding areas for particles representing feeding larvae of western Baltic cod (Figure 2; Supplementary Figure S1) were generally only partly located within their original spawning grounds but showed a high degree of spatial overlap between areas of origin (Table 1, Figure 2). For the Kattegat spawners, larval release areas were generally also located in the south-central Kattegat, as well as north of the initial spawning area along the Swedish west coast (Figure 2). Offspring originating in the Sound were generally not found in the Sound at the end of the yolk-sac stage, but in the southern and central Kattegat, resulting in a high degree of overlap with the Kattegat release area (Figure 2). A large part of offspring originating in the Great Belt was also found to be located in the original spawning ground at the end of the endogenously feeding period, but there was also a relatively high degree of spatial overlap with the larval release areas of offspring of Kattegat and Sound origin in the south-central Kattegat (Figure 2). Compared with the three other spawning areas, offspring originally spawned in the Kiel Bight and Mecklenburg Bay were found to be closer connected to their initial spawning area, covering the eastern part of Kiel Bay and parts of the Mecklenburg Bay, however, there was also a certain degree of spatial overlap with the larval release area of Great Belt offspring (Figure 2).

\section{Particle end positions}

The model runs conducted in the present study addressed the question how many particles, representing different larval cohorts originating in the different western Baltic cod spawning grounds (Figure 1) ended up within the different ICES Subdivisions of the western and the central Baltic Sea. A sensitivity analysis of particle depth on drift patterns showed that depth of occurrence has an impact on drift direction and distance. The deeper the particles, the further were they transported towards the east (Supplementary Figure S2). At present, no information exists on the vertical migration patterns of larvae in the Kattegat/western Baltic Sea, and drift patterns of larvae are therefore integrated over the entire depth range where they have been observed in the field (Westerberg, 1994). Time series of yearly averages of retention within release areas and dispersal

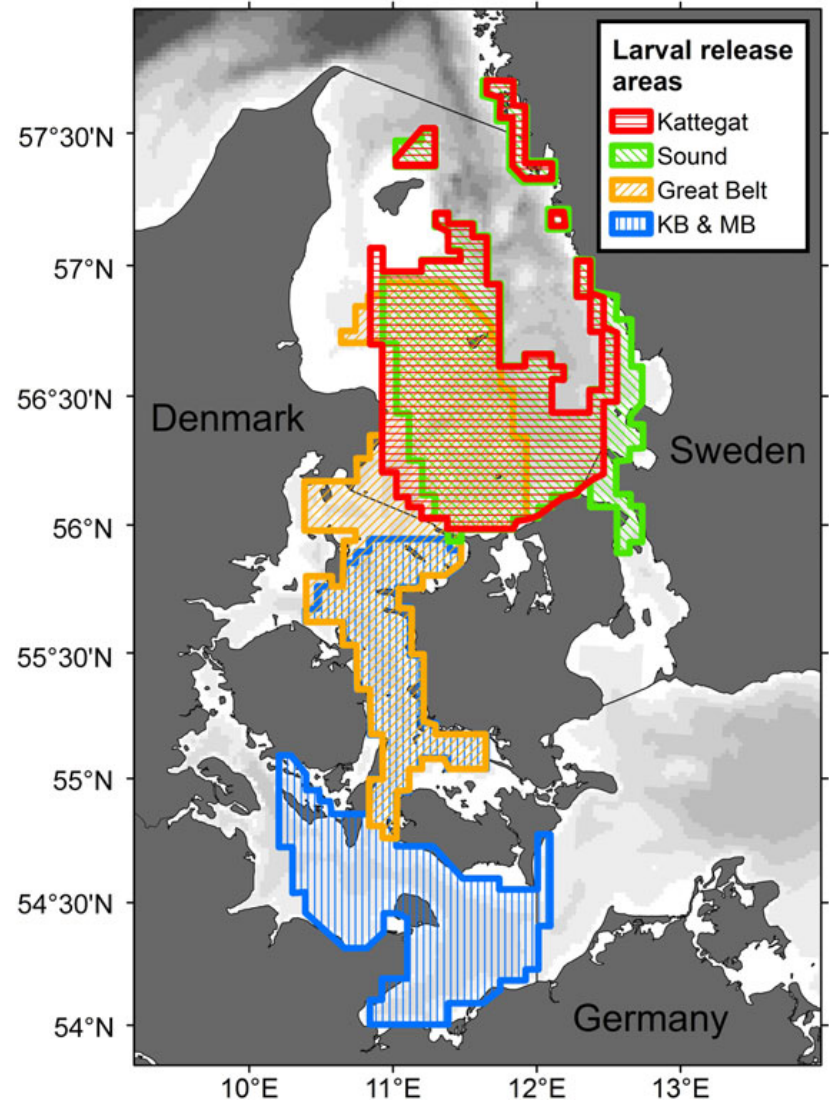

Figure 2. Extent and overlap of release areas of larvae originating in the four spawning grounds in Kattegat, Sound, Great Belt, and Kiel \& Mecklenburg Bay. For a colour representation of the figure, it is referred to the online version. This figure is available in black and white in print and in colour at ICES Journal of Marine Science online.

to adjacent areas for the entire spawning season (Figure $3 a-d$ ) and seasonally resolved for the early, mid, and late spawning season (Supplementary Figures S3-S6) are presented, as well as averages and standard deviations of proportions of final drift destinations in the different areas for all years from 1979 to 2004 in early, mid, late, and total spawning season (Table 2).

Particles initially released in the Kattegat did mainly end up in the Kattegat and Skagerrak, with high interannual variability (Figure 3a, Table 2). In the 1980s, a particularly strong northward drift occurred, with a very large share of particles transported into Skagerrak, reaching values between 50 and $60 \%$, while fewer particles stayed in Kattegat. Since the 1990s, relatively stable shares of $40-50$ and $10-15 \%$ were transported to Skagerrak and Kattegat and south into SD22, respectively, whereas only very few particles were transported to the more eastern subdivisions $24-28$. On average, $46 \%$ of particles were transported to Skagerrak, $12 \%$ to SD 22, $2 \%$ to SD $24,1 \%$ to SD 25 and $<1 \%$ to SDs 23, 26 and 28, while 38\% stayed in Kattegat (Table 2).

The particles released in the Sound show a very similar pattern as the particles released in Kattegat (Figure 3b), with almost identical average shares of particles ending in the different areas (Table 2). This means that there was basically no retention of particles in the Sound $(0.6 \pm 0.2 \%)$. Instead, all offspring originating in this area were transported into adjacent areas, with on average $>80 \%$ in northern direction ( $45 \%$ to SD20 and 38\% to SD 21 ), a smaller share of $12 \%$ towards south in SD 22 and very few further east. Another 

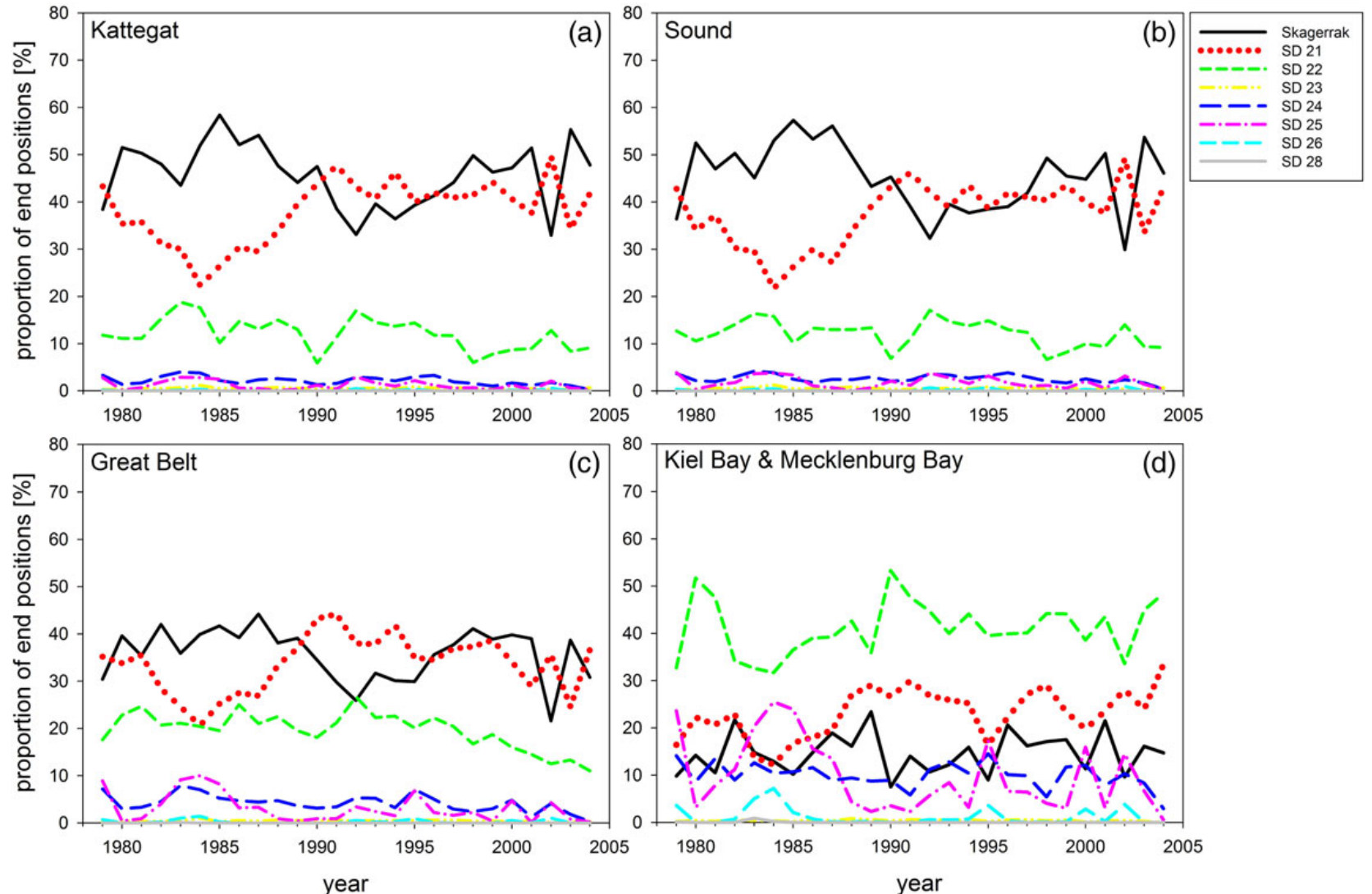

Figure 3. Time series of proportions of particles ending in Skagerrak and ICES SD's 21-28 for particles originating in (a) Kattegat, (b) Sound, (c) Great Belt, and (d) Kiel \& Mecklenburg Bay. For a colour representation of the figure, it is referred to the online version. This figure is available in black and white in print and in colour at ICES Journal of Marine Science online.

Table 2. Averages and standard deviations (1979-2004) of proportions [\%] of particle end positions by initial spawning areas and destination areas for early (December-January), mid (February-March), late (April-June), and total (December-June) spawning season.

\begin{tabular}{|c|c|c|c|c|c|c|c|c|c|}
\hline \multirow[b]{2}{*}{ Release area } & \multirow[b]{2}{*}{ Release period } & \multicolumn{8}{|c|}{ Destination area } \\
\hline & & Skagerrak & SD21 & SD22 & SD23 & SD24 & SD25 & SD26 & SD28 \\
\hline \multirow[t]{4}{*}{ Kattegat (SD 21) } & Early & $45.6 \pm 12.0$ & $35.2 \pm 9.2$ & $13.4 \pm 4.8$ & $0.8 \pm 0.3$ & $2.9 \pm 1.9$ & $2.0 \pm 2.1$ & $0.2 \pm 0.5$ & $0.0 \pm 0.0$ \\
\hline & Middle & $51.5 \pm 10.8$ & $37.4 \pm 10.0$ & $8.2 \pm 3.6$ & $0.4 \pm 0.4$ & $1.4 \pm 1.3$ & $1.1 \pm 1.4$ & $0.1 \pm 0.1$ & $0.0 \pm 0.0$ \\
\hline & Late & $39.2 \pm 9.2$ & $42.3 \pm 7.3$ & $15.3 \pm 6.1$ & $0.6 \pm 0.4$ & $2.2 \pm 1.3$ & $0.6 \pm 1.0$ & $0.0 \pm 0.0$ & $0.0 \pm 0.0$ \\
\hline & Total & $45.8 \pm 6.8$ & $38.1 \pm 6.8$ & $12.1 \pm 3.4$ & $0.6 \pm 0.2$ & $2.2 \pm 0.9$ & $1.2 \pm 1.0$ & $0.1 \pm 0.2$ & $0.0 \pm 0.0$ \\
\hline \multirow[t]{4}{*}{ Sound (SD 23) } & Early & $45.1 \pm 12.2$ & $34.7 \pm 9.0$ & $13.5 \pm 4.6$ & $0.6 \pm 0.3$ & $3.3 \pm 2.0$ & $2.6 \pm 2.6$ & $0.3 \pm 0.7$ & $0.0 \pm 0.0$ \\
\hline & Middle & $50.0 \pm 10.6$ & $37.5 \pm 9.6$ & $9.0 \pm 3.5$ & $0.4 \pm 0.4$ & $1.7 \pm 1.3$ & $1.4 \pm 2.6$ & $0.2 \pm 0.3$ & $0.0 \pm 0.0$ \\
\hline & Late & $37.0 \pm 8.9$ & $42.0 \pm 7.1$ & $15.7 \pm 4.9$ & $0.9 \pm 0.6$ & $3.2 \pm 1.4$ & $1.4 \pm 1.8$ & $0.0 \pm 0.0$ & $0.0 \pm 0.0$ \\
\hline & Total & $45.3 \pm 7.2$ & $37.5 \pm 6.8$ & $12.1 \pm 2.8$ & $0.6 \pm 0.2$ & $2.6 \pm 0.9$ & $1.8 \pm 1.2$ & $0.2 \pm 0.3$ & $0.0 \pm 0.0$ \\
\hline \multirow{4}{*}{ Great Belt (SD $22 \mathrm{~N}$ ) } & Early & $31.5 \pm 10.2$ & $31.6 \pm 8.1$ & $27.4 \pm 6.6$ & $0.6 \pm 0.4$ & $4.8 \pm 2.9$ & $3.7 \pm 4.4$ & $0.4 \pm 0.8$ & $0.0 \pm 0.0$ \\
\hline & Middle & $42.6 \pm 10.6$ & $36.3 \pm 8.5$ & $14.3 \pm 4.3$ & $0.3 \pm 0.3$ & $3.4 \pm 2.1$ & $3.0 \pm 3.7$ & $0.2 \pm 0.4$ & $0.0 \pm 0.0$ \\
\hline & Late & $33.4 \pm 11.0$ & $36.9 \pm 6.8$ & $21.6 \pm 6.9$ & $0.4 \pm 0.3$ & $5.2 \pm 2.8$ & $2.7 \pm 3.6$ & $0.0 \pm 0.1$ & $0.0 \pm 0.0$ \\
\hline & Total & $35.8 \pm 5.5$ & $33.7 \pm 6.1$ & $19.7 \pm 3.9$ & $0.4 \pm 0.2$ & $4.2 \pm 1.8$ & $3.1 \pm 3.1$ & $0.3 \pm 0.4$ & $0.0 \pm 0.0$ \\
\hline \multirow[t]{4}{*}{$K B \& M B(S D 22 S)$} & Early & $8.2 \pm 4.2$ & $16.4 \pm 6.1$ & $50.4 \pm 11.8$ & $0.6 \pm 0.5$ & $11.4 \pm 5.3$ & $11.3 \pm 10.7$ & $1.9 \pm 3.9$ & $0.0 \pm 0.1$ \\
\hline & Middle & $19.2 \pm 9.4$ & $26.3 \pm 7.9$ & $35.9 \pm 6.9$ & $0.2 \pm 0.1$ & $8.2 \pm 3.9$ & $9.0 \pm 8.8$ & $1.3 \pm 2.3$ & $0.1 \pm 0.4$ \\
\hline & Late & $15.0 \pm 7.0$ & $25.7 \pm 4.5$ & $38.7 \pm 7.5$ & $0.4 \pm 0.4$ & $11.1 \pm 4.0$ & $9.0 \pm 6.9$ & $0.3 \pm 0.5$ & $0.0 \pm 0.0$ \\
\hline & Total & $14.7 \pm 4.3$ & $23.1 \pm 5.3$ & $41.2 \pm 5.9$ & $0.4 \pm 0.2$ & $10.0 \pm 2.7$ & $9.7 \pm 7.6$ & $1.2 \pm 1.9$ & $0.0 \pm 0.2$ \\
\hline
\end{tabular}

interesting fact about the Sound is that this area did basically not receive any particles from adjacent areas either, with total average values of particles ending in SD 23 ranging between 0.4 and $0.6 \%$.

Particles released in the Great Belt in the northern part of SD 22 also showed similar general drift patterns as Kattegat and Sound, with high interannual variability and a generally high transport towards north (Table 2, Figure 3c). Also for this release area, northward drift was particularly pronounced during the 1980s when a higher fraction was transported to Skagerrak than to Kattegat, while during the early 1990s more particles ended in Kattegat than in Skagerrak. Since the mid-1990s more or less equal shares ended in Skagerrak and Kattegat. However, the overall share of particles 
transported to Skagerrak and Kattegat was $\sim 35 \%$ and thus smaller than for particles released in Kattegat and the Sound, while there was a higher share of retention within SD 22 (on average ca. 20\%). Also, a higher average share of 4 and 3\% were drifted eastward to SD 24 and SD 25, respectively, with some years (e.g. 1979, 1983-1985, 1995) ranging between 5 and $10 \%$.

Particles released in Kiel Bay and Mecklenburg Bay in the southern part of SD 22 showed the highest retention (41\%) of all four investigated release areas (Table 2, Figure 3d). However, also from this area considerable shares of on average 15 and $20 \%$ were transported to Skagerrak and Kattegat. Furthermore, this area also showed a high variability with respect to drift into other areas, with some years characterized by high shares of northward drift and others by high shares of eastward drift. This variability becomes particularly evident when comparing the time series for SD 21 and SD25, which were showing alternating patterns, with low transport to SD 25 and high transport to SD 21 in 19801982, 1988-1994, and 1996-1999 and an opposite pattern in $1979,1983-1985,1995$, and 2000 . In these latter years up to $26 \%$ were transport to SD 25 and up to 7\% reached as far east as SD 26. The high interannual variability of transport to SD 25 is also witnessed by the high standard deviation of 7.6 at an average of $9.7 \%$ (Table 2). In contrast to the alternating pattern between SD 21 and SD 25, northward transport to Skagerrak and eastward transport to SD 24 were rather stable at values of ca. 10-20 and 10$15 \%$, respectively. It should also be noted that SD 24 belongs to the same management unit as SD 22, which means if particles ending in SD 22 and SD 24 are combined, more than half of the particles released in Kiel and Mecklenburg Bay were retained within that management unit.

To further illustrate the potential for variability in transport between areas, we have mapped two extreme examples of eastward and northward transport for particles released in the Kiel and Mecklenburg Bay area (see Supplementary Figure S7a and b).

\section{Comparison of particle end positions with spatial distribution of juvenile cod}

For particles initially released in the Kattegat, there is a good match between large numbers of particle end positions (Figure $4 \mathrm{a}$ ) and abundance of juvenile cod (Figure 4d) at the border between Kattegat and Skagerrak, as well as in the eastern Skagerrak along the coast of Sweden. A large number of particles ended also in the central Skagerrak, but for this area no trawl data were available for comparison with juvenile occurrence.

Within the Kattegat, there is a good spatial match, with high abundance of particle end positions and juveniles in the southeastern Kattegat, while lower values of particles in the western part of the Kattegat correspond to low or zero catches of juveniles. However, when considering the overall picture of all particles and juvenile abundance in the entire investigation area, the proportions do not match well, as there is a low juvenile abundance in the southeastern Kattegat compared with the large numbers of particles in this area.

Particles initially released in the Sound show an almost identical pattern as particles released in the Kattegat, and therefore no separate map is shown for this release area.

Particles initially released in the Great Belt also show a similar pattern as particles released in the Kattegat and the Sound (Figure 4b), with centres of aggregations along the Swedish Skagerrak coast, at the border between Skagerrak and Kattegat and in the southeastern Kattegat. However, there are also areas of increased accumulations of particles in the southwestern Kiel Bay as well as in the central Mecklenburg Bay, which matches high juvenile abundances in these areas.

Finally, for the release area Kiel Bay and Mecklenburg Bay, there is a good match between particle end positions and juvenile cpues in the southern part of the study area, with high accumulations in the western and southern Kiel Bay as well as in central parts of Mecklenburg Bay (Figure $4 \mathrm{c}$ and d).

\section{Discussion \\ Larval drift, hydrography, juvenile nursery areas, and connectivity}

Connectivity, or the exchange of individuals among populations, is an important process from an ecological perspective, but also for conservation and management of harvested species (e.g. Selkoe et al., 2008; Cowen and Sponaugle, 2009; Reiss et al., 2009). The connectivity of Atlantic cod (Gadus morhua) populations in the transition area between the North Sea and the Baltic has been the topic of a number of studies (Pihl and Ulmestrand, 1993; Nielsen et al., 2003, 2005; Svedäng and Svenson, 2006; Svedäng et al., 2007, 2010a, b). However, these investigations were focused on migrations and genetic structure of adults and larger juveniles, while transport of early life stages has not been considered, although pelagic eggs and larvae can be transported over large distances via ocean currents. In previous studies, Hüssy et al. (2012), Hinrichsen et al. (2012), and Pacariz et al. (2014a, b) have analysed the fate of cod eggs and yolk-sac larvae in this transition area. These studies showed that environmentally mediated mortality and survival success were predominantly affected by egg buoyancy, ambient temperatures, and transport into suitable or unsuitable habitats, and that transport patterns are highly variable within and between years, with average transport directions towards the north.

As for the egg stage, the transport patterns during the exogenously feeding larval stage investigated in the present study were generally also very dynamic and showed high intra- and interannual variability of particle end positions. However, recurring patterns of larval transport were found, e.g. the general drift in northward direction for the three northern spawning areas and the high retention for the spawning area in Kiel Bay and Mecklenburg Bay. Furthermore, a striking feature of our modelling study was the high overlap of larval release areas in the middle (February-March) and partly also the early (December-January) spawning season, while late in the spawning period April-June) the larval release areas were more distinct with only little overlap. This can be related to lower ambient temperatures in mid and partly also early season and the correspondingly longer temperature-dependent egg and yolk-sac larval developmental times associated with longer drift durations resulting in larger drift distances. In contrast, higher ambient temperatures associated with shorter development times and shorter drift durations at the end of the spawning season (Hinrichsen et al., 2012) resulted in smaller release areas for feeding larvae, which were more concentrated near the initial spawning areas. Another interesting result was that the Sound showed basically no retention but transport of $>80 \%$ of particles towards the north, and generally an identical drift pattern as the Kattegat. This is caused by the fact that eggs spawned in the Sound are more or less immediately flushed northward into the Kattegat (Hinrichsen et al., 2012) and the release area of larvae initially originating in the Sound is therefore very similar to the release area of larvae from the Kattegat spawning ground. 

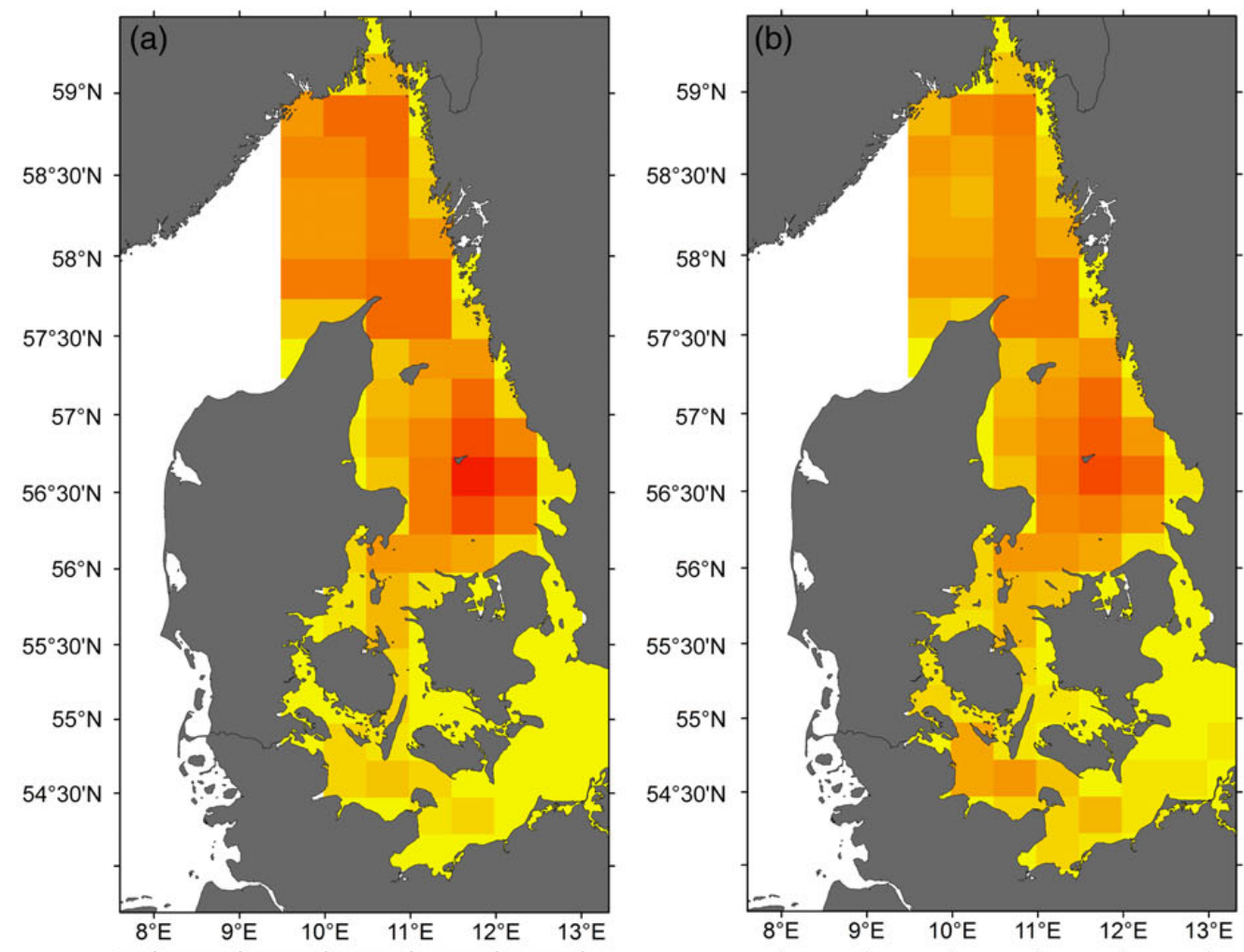

Particles [\%]

$0.0005-0.25$

민 $0.2501-0.50$

$0.5001-0.75$

] $0.7501-1.00$

- $1.0001-1.25$

$1.2501-1.50$

- $1.5001-1.75$

$1.7501-2.00$

2.0001-2.25

- $2.2501-2.50$

$2.5001-2.75$

2.7501- 3.00

$3.0001-3.25$

$3.2501-3.50$

- $3.5001-3.75$

3.7501- 4.00

- $4.0001-4.25$
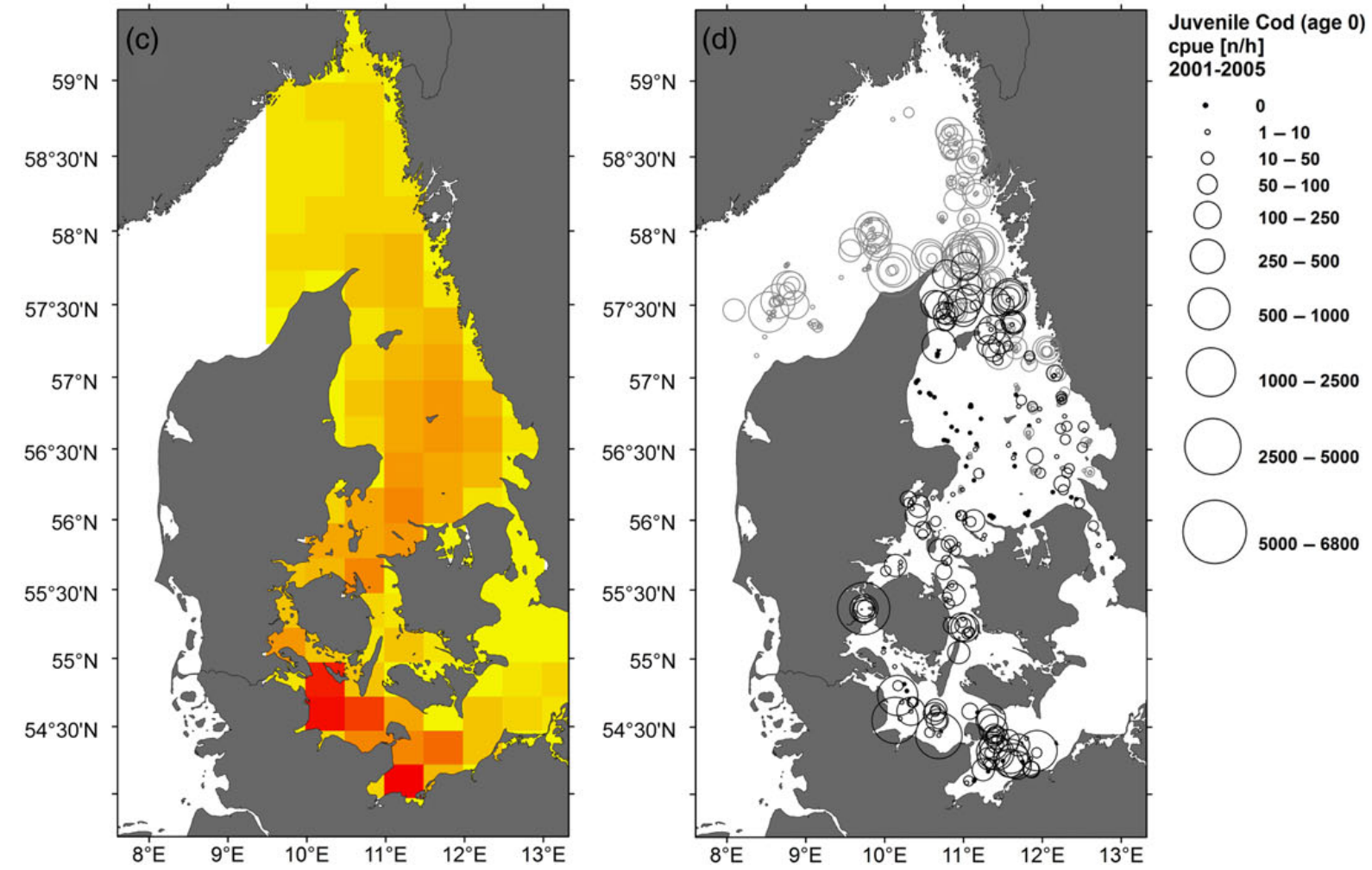

Figure 4. Comparison of average (1979-2004) particle end positions (\%) for particles released in (a) Kattegat, (b) Great Belt, and (c) Kiel \& Mecklenburg Bay with (d) catch per unit effort (cpue, $n$ / hour) of juvenile cod from bottom trawl surveys (grey circles: IBTS - International Bottom Trawl Survey, black circles: BITS - Baltic International Trawl Survey) in the period 2001-2005. For a colour representation of the figure, it is referred to the online version. This figure is available in black and white in print and in colour at ICES Journal of Marine Science online.

The comparison of particle end positions with catches of juvenile cod from bottom trawl surveys showed a high degree of concurrence, with centres of nursery areas around Skagen at the northern tip of Denmark and along the Swedish coast, as well as in Kiel and Mecklenburg Bay. However, there were also some discrepancies with large numbers of particles but no concurrent juvenile 
occurrence in the central Skagerrak, which can be explained by the local topography. Although not sampled in the IBTS, juvenile cod are likely not able to find a suitable settling habitat in this area due to the large depths in the eastern part of the Norwegian Trench. Considering Kattegat alone, there is actually a good spatial match, with a juvenile nursery area in the southeast and no juvenile occurrence in the western part. However, the proportions of particles and juvenile catches did not agree well, with relatively low juvenile catches compared with the large number of particles ending in this area. This may be related to the fact that the exchange rates between areas and the associated particle end positions represent relative, general patterns rather than actual abundances, as no information on spawning intensity and estimates of actual numbers of eggs and larvae released in the different spawning areas were available. Furthermore, there is an important difference between "total connectivity", i.e. the number of transported particles and "realized connectivity", i.e. the number of transported particles which actually survive and contribute to successful recruitment and eventually reproduction (Selkoe et al., 2008). This issue has at least partly been considered in our previous studies on cod eggs, which estimated egg mortality due to unfavourable environmental conditions in the spawning areas and along the drift routes (Hinrichsen et al., 2012; Hüssy et al., 2012). However, analyses of realized connectivity during the larval stage would require estimates of larval mortality by linking the drift model with a bioenergetics growth model and realistic prey fields as well as absolute measures of initially released eggs and their attributes (i.e. size, buoyancy) based on spawning stock size, stock composition and fecundity. As these necessary data and tools for estimation of absolute numbers are not available, drift patterns can at present only be captured as probability distributions. Nevertheless, the overall good agreement between spatial patterns of particle end positions and juvenile catches suggests that our modelling study provides reasonable estimates of larval drift and juvenile settling areas, and thus of general patterns of early life stage connectivity between cod populations in the investigated areas, while the actually realized connectivity between areas awaits further quantification.

The strong differences of retention and dispersal patterns of larval cod in space and time are a consequence of the specific, spatially, and temporally highly variable physical environmental conditions in our study area, which in turn lead to a highly dynamic ocean circulation (for details, see e.g. Stigebrandt, 1983; Schinke and Matthäus, 1998; Lehmann et al., 2002). The combination of these highly variable environmental conditions with the small size and close vicinity of the cod management units in the transition area between North Sea and Baltic lead to a high potential for exchange of individuals between management units via advective transport during the pelagic stages of the life cycle.

\section{Evidence of stock structure in the transition area between North Sea and Baltic}

In the transition area between the North Sea and the Baltic Sea there is ample evidence of complex stock structuring from area-specific stock indices (Svedäng and Svenson, 2006; Svedäng et al., 2010a), tagging experiments (Pihl and Ulmestrand, 1993; Svedäng et al., 2007), chemical signatures in otoliths (Svedäng et al., 2010b), and genetics (Nielsen et al., 2003). Cod in the Kattegat (SD 21) consist of a mixture of resident and migratory stocks undertaking migrations as far as the North Sea (Svedäng et al., 2007). Throughout the area from the Belt Sea (SD 22) to the Arkona Basin (SD 24) spawning migrations occur towards the southern Kattegat and Great Belt, respectively, with return migrations to their respective feeding grounds (Hüssy, 2011 and references therein). In the Sound however, cod seem to be exclusively resident (Svedäng et al., 2007).

Despite this apparent stock structuring driven by individual fish's behaviour, there seems to be limited genetic differentiation. While North Sea, Kattegat, Sound, and Belt Sea cod are genetically similar (Nielsen et al., 2003; Svedäng et al., 2010b), they differ significantly from cod in the Baltic Sea east of Bornholm (Nielsen et al., 2003). To explore the connectivity between stocks from different areas, Nielsen et al. (2005) examined the genetic linkage between adults and juveniles within each area. Juvenile cod in the North Sea, Kattegat/Skagerrak, Belt Sea, and Eastern Baltic are genetically related to adults in the same areas indicative of limited exchange with other areas. Juveniles from the Western Baltic Sea on the other hand were closer related to adults from the Belt Sea (Nielsen et al., 2005). This suggests early life stage dispersal from the Belt Sea towards the east. Additionally, a number of genetically distinct local populations occur along the Skagerrak coast, with no apparent trend of isolation by distance. This suggests that the primary driver for genetic stock structuring is not migration of adults but drift of early life stages without subsequent return migration as juveniles or adults (Knutsen et al., 2003).

Extensive and temporally variable drift of North Sea cod larvae into coastal waters in the Skagerrak are known to occur, and between 1 and $10 \%$ of juveniles in the Skagerrak were estimated to be of North Sea origin (Knutsen et al., 2004; Stenseth et al., 2006). In combination with results from the present study, this suggests that the Skagerrak/Kattegat may be an area where cod originating in the North Sea, the Skagerrak, the Kattegat, and the western Baltic are mixing via larval drift, while the eastern Baltic is isolated through limited exchange of both early life stages and adults.

Although there is evidence of a certain degree of natal homing in cod in the area of investigation, the lack of genetic differentiation documents that extensive gene flow occurs between stocks in the transition area between the North Sea and the western Baltic. The high dispersal rates between areas observed in the present study suggest that dispersal of early life stages may be the driving force for this lack in genetic differentiation.

\section{Implications for fisheries management}

Hinrichsen et al. (2011) documented the usefulness of hydrodynamic and coupled biophysical models for fisheries management, owing to their ability to estimate the transport and survival chances of early life stages, the settlement probability of juvenile fish and the spatio-temporal scales of connectivity between stocks.

Stock identity and geographical boundaries used to define fish stocks are of particular concern for fisheries management as a failure to recognize biological populations could result in nonoptimal or unsustainable management of the resources (Heath et al., 2013; Eero et al., 2014). Development of various stock separation techniques can potentially allow accounting for mixing of biological populations in stock assessment, as demonstrated by a recent example for Eastern and Western Baltic cod (Hüssy et al., 2015; ICES $2015 \mathrm{a}, \mathrm{c})$. Our analyses in the present paper demonstrate that the stock structure in the transition area between North Sea and Baltic may be even more complex when considering early life stages and involve four different cod management units: Skagerrak/North Sea, Kattegat, Western Baltic, and Eastern Baltic.

Evaluations of fishing opportunities based on stock assessments are mostly focused on the adult components of the stocks. The exchange of offspring between different stock assessment or 
management units may not be an issue for assessing the adult biomass levels or fishing pressure, given that homing takes place (Robichaud and Rose, 2001; Svedäng et al., 2007). However, the relationship between parent stock biomass and resulting recruitment is an important basis for defining biological reference points used for fisheries management. Stock-recruitment relationships may be blurred extensively if large parts of the eggs and larvae spawned in a given management unit do not remain as recruits in the same area, but instead contribute as recruits to adjacent stock units. Exchange of recruits needs to be considered for small adjacent assessment units with extensive water movement as demonstrated in this study for the transition area from the North Sea to the Baltic. Drift of early life stages can thus be one of the reasons for the lack of well-defined relationships between recruitment and the size of parent stock within the assessment units, in addition to drivers affecting recruitment survival.

The "realized connectivity" (Selkoe et al., 2008), i.e. the numbers of transported particles which actually survive and contribute to recruitment in the investigated cod stock areas, is currently not quantified. Therefore, it is difficult to evaluate the magnitude of the potential problem that the apparently substantial drift of early life stages causes for stock assessment and management. However, given the high probability of substantial exchange of recruits between the defined assessment units, stock-recruitment relationships within a given unit should be treated with caution. Quantitative analyses of the origin of recruitment in different areas are recommended as a next step, for example, using otolith chemistry (Svedäng et al., 2010b). Furthermore, studies on larval vertical migration behaviour and regular ichthyoplankton surveys are advocated to improve the input for drift modelling and to further quantify connectivity between areas.

From a management point of view, one could consider combining the smaller units into one single assessment covering a larger geographical area to avoid violating the closed population assumption that is the basis for stock assessment. However, a shortcoming of this approach is that weaker subpopulations may not get sufficiently protected as the most abundant substock will mask the developments in smaller populations (e.g. Eero et al., 2014). In fact, a number of recent studies have argued for a finer spatial resolution in fisheries management to account for subpopulations structure, e.g. for cod in the North Sea (Heath et al., 2013). Ideally, spatial processes should be modelled as part of stock assessment, which however increases the complexity of stock assessments and data demands (Goethel et al., 2011). Thus, there is a need for both better understanding of connectivity to quantify the exchange of recruits between areas as well as further development of stock assessment modelling tools to identify most appropriate solutions for stock assessment and fisheries management purposes taking into account spatial processes.

Hydrodynamic and coupled biophysical models such as the one used in this study are considered valuable tools to estimate spatiotemporal scales of connectivity within and between stocks, to identify potential issues with stock area definitions and thereby to contribute to conservation, management, and recovery of fish stocks.

\section{Supplementary material}

Supplementary material is available at the ICESJMS online version of the paper.

\section{Acknowledgements}

This study was financed and conducted as part of the International Femern Belt Science Provision Contract. The research leading to these results has also received funding from BONUS (INSPIRE and BIO-C3 projects), the joint Baltic Sea research and development programme (Art 185), funded jointly from the European Union's Seventh Programme for research, technological development, and demonstration (Forschungszentrum Jülich Beteiligungsgesellschaft $\mathrm{mbH}$ (Germany) and from the Innovation Fund Denmark.

\section{References}

Baumann, H., Hinrichsen, H-H., Möllmann, C., Köster, F. W., Malzahn, A. M., and Temming, A. 2006. Recruitment variability in Baltic sprat (Sprattus sprattus) is tightly coupled to temperature and transport patterns affecting the larval and early juvenile stages. Canadian Journal of Fisheries and Aquatic Sciences, 63: 2191-2201.

Bergstrøm, S., and Carlsson, B. 1994. River runoff to the Baltic Sea: 1950-1990. Ambio, 23: 280-287.

Bryan, K. 1969. A numerical method for the study of the circulation of the world ocean. Journal of Physical Oceanography, 15: 1312-1324.

Cowen, R. K., and Sponaugle, S. 2009. Larval dispersal and marine population connectivity. Annual Review of Marine Science, 1: 443-466.

Cox, M. D. 1984. A primitive equation 3-dimensional model of the ocean. GFDL Ocean Group Technical Report No. 1, Geophysical Fluid Dynamics Laboratory, Princeton, NJ, 75 pp.

Edwards, K. P., Werner, F. E., Seim, H., and Hare, J. A. 2007. Using 2-dimensional dispersal kernels to identify the dominant influences on larval dispersal on continental shelves. Marine Ecology Progress Series, 352: 77-87.

Eero, M., Hemmer-Hansen, J., and Hüssy, K. 2014. Implications of stock recovery for a neighbouring management unit: experience from the Baltic cod. ICES Journal of Marine Science, 71: 1458-1466.

Gaines, S. D., and Lafferty, K. D. 1995. Modeling the dynamics of marine species: the importance of incorporating larval dispersal. In Ecology of Marine Invertebrate Larvae, pp. 389-412. Ed. by L. R. McEdward. CRC Press, Boca Raton, FL, USA.

Gaylord, B., and Gaines, S. D. 2000. Temperature or transport? Range limits in marine species mediated solely by flow. American Naturalist, 155: 769-789.

Goethel, D. R., II, Quinn, T., and Cadrin, S. X. 2011. Incorporating spatial structure in stock assessment: Movement modeling in marine fish population dynamics. Reviews in Fisheries Science, 19: 119-136.

Grosberg, R. K., and Cunningham, C. W. 2001. Genetic structure in the sea: from populations to communities. In Marine Community Ecology, pp. 61-84. Ed. by M. D. Bertness, M. E. Hay, and S. D. Gaines. Sinauer, Sunderland, MA, USA.

Gulland, J. A. 1983. Fish stock assessment: a manual of basic methods. FAO Wiley Series on food and agriculture. Vol. 1. Wiley Interscience, Chichester, UK. 223 pp.

Heath, M. R., Culling, M. A., Crozier, W. W., Fox, C. J., Gurney, W. S. C., Hutchinson, W. F., Nielsen, E. E., et al. 2013. Combination of genetics and spatial modelling highlights the sensitivity of cod (Gadus morhua) population diversity in the North Sea to distributions of fishing. ICES Journal of Marine Science, 71: 794-807.

Hinrichsen, H-H., Boettcher, U., Oeberst, R., Voss, R., and Lehmann, A. 2001. The potential for advective exchange of the early life stages between the western and eastern Baltic cod (Gadus morhua L.) stocks. Fisheries Oceanography, 10: 249-258.

Hinrichsen, H-H., Dickey-Collas, M., Huret, M., Peck, M. A., and Vikebø, F. B. 2011. Evaluating the suitability of coupled biophysical models for fishery management. ICES Journal of Marine Science, 68: 1478-1487.

Hinrichsen, H-H., Hüssy, K., and Huwer, B. 2012. Spatio-temporal variability in western Baltic cod early life stage survival mediated by egg buoyancy, hydrography and hydrodynamics. ICES Journal of Marine Science, 69: 1744-1752. 
Hinrichsen, H-H., Lehmann, A., St. John, M. S., and Brügge, B. 1997. Modeling the cod larvae drift in the Bornholm Basin in summer 1994. Continental Shelf Research, 17: 1765-1784.

Hixon, M. A., Pacala, S. W., and Sandin, S. A. 2002. Population regulation: historical context and contemporary challenges of open vs closed systems. Ecology, 83: 1490-1508.

Hüssy, K. 2011. Review of western Baltic cod (Gadus morhua) recruitment dynamics. ICES Journal of Marine Science, 68: 1459-1471.

Hüssy, K., Hinrichsen, H-H., Eero, M., Mosegaard, H., Hemmer-Hansen, J., Lehmann, A., and Lundgaard, L. S. 2015. Spatio-temporal trends in stock mixing of eastern and western Baltic cod in the Arkona Basin and the implications for recruitment (under revision). doi: 10.1093/icesjms/fsv227.

Hüssy, K., Hinrichsen, H-H., and Huwer, B. 2012. Hydrographic influence on the spawning habitat suitability of western Baltic cod (Gadus morhua). ICES Journal of Marine Science, 69: 1736-1743.

Huwer, B., Hinrichsen, H-H., Böttcher, U., Voss, R., and Köster, F. W. 2014. Characteristics of juvenile survivors reveal spatio-temporal differences in early life stage survival of Baltic cod. Marine Ecology Progress Series, 511: 165-180.

ICES. 2005. Spawning and life history information for North Atlantic cod stocks. ICES Cooperative Research Report No. 274. 152 pp.

ICES. 2015a. Report of the Baltic Fisheries Assessment Working Group (WGBFAS), 14-21 April 2015, ICES Headquarters, Copenhagen, Denmark. ICES CM 2015/ACOM:10.

ICES. 2015b. Report of the International Bottom Trawl Survey Working Group (IBTSWG), 23-27 March 2015, Bergen, Norway. ICES CM 2015/SSGIEOM:24. 278 pp.

ICES. 2015c. Report of the Benchmark Workshop on Baltic Cod Stocks (WKBALTCOD). ICES CM 2015/ACOM:35.

Killworth, P. D., Stainforth, D., Webbs, D. J., and Paterson, S. M. 1991. The development of a free-surface Bryan-Cox-Semtner ocean model. Journal of Physical Oceanography, 21: 1333-1348.

Knutsen, H., André, C., Jorde, P. E., Skogen, M. D., Thuróczy, E., and Stenseth, N. C. 2004. Transport of North Sea cod larvae into the Skagerrak coastal populations. Proceedings of the Royal Society B-Biological Sciences, 271: 1337-1344.

Knutsen, H., Jorde, P. E., André, C., and Stenseth, N. C. 2003. Fine-scaled geographical population structure in a highly mobile marine species: the Atlantic cod. Molecular Ecology, 12: 385-394.

Lehmann, A. 1995. A three-dimensional baroclinic eddy-resolving model of the Baltic Sea. Tellus, 47A: 1013-1031.

Lehmann, A., and Hinrichsen, H-H. 2000. On the thermohaline variability of the Baltic Sea. Journal of Marine Systems, 25: 333-357.

Lehmann, A., Krauß, W., and Hinrichsen, H-H. 2002. Effects of remote and local atmospheric forcing on circulation and upwelling in the Baltic Sea. Tellus, 54: 299-316.

Nielsen, E. E., Grønkjær, P., Meldrup, D., and Paulsen, H. 2005. Retention of juveniles within a hybrid zone between North Sea and Baltic Sea Atlantic cod (Gadus morhua). Canadian Journal of Fisheries and Aquatic Sciences, 62: 2219-2225.

Nielsen, E. E., Hansen, M. M., Ruzzante, D. E., Meldrup, D., and Grønkjær, P. 2003. Evidence of a hybrid-zone in Atlantic cod (Gadus morhua) in the Baltic and the Danish Belt Sea revealed by individual admixture analysis. Molecular Ecology, 12: 1497-1508.
Pacariz, S., Björk, G., Jonsson, P., Börjesson, P., and Svedäng, H. 2014a. A model study of the large-scale transport of fish eggs in the Kattegat in relation to egg density. ICES Journal of Marine Science, 71: $345-355$.

Pacariz, S., Björk, G., and Svedäng, H. 2014b. Interannual variability in the transport of fish eggs in the Kattegat and Öresund. ICES Journal of Marine Science, 71: 1706-1716.

Palumbi, S. R. 2004. Marine reserves and ocean neighborhoods: the spatial scale of marine populations and their management. Annual Review of Environment and Resources, 29: 31-68.

Pihl, L., and Ulmestrand, M. 1993. Migration pattern of juvenile cod (Gadus morhua) on the Swedish west coast. ICES Journal of Marine Science, 50: 63-70.

Reiss, H., Hoarau, G., Dickey-Collas, M., and Wolff, W. J. 2009. Genetic population structure of marine fish: mismatch between biological and fisheries management units. Fish and Fisheries, 10: 361-395.

Robichaud, D., and Rose, G. A. 2001. Multiyear homing of Atlantic cod to a spawning ground. Canadian Journal of Fisheries and Aquatic Sciences, 58: 2325-2329.

Roughgarden, J., Gaines, S., and Possingham, H. 1988. Recruitment dynamics in complex life cycles. Science, 241: 1460-1466.

Schinke, H., and Matthäus, W. 1998. On the causes of major Baltic inflows - an analysis of long time series. Continental Shelf Research, 18: 67-97.

Selkoe, K. A., Henzler, C. M., and Gaines, S. D. 2008. Seascape genetics and the spatial ecology of marine populations. Fish and Fisheries, 9: 363-377.

Semtner, A. J. 1974. A general circulation model for the World Ocean. UCLA Department of Meteorology Technical Report, No. 8, 99 pp.

Sinclair, M. 1988. Marine populations: an essay on population regulation and speciation. University of Washington Press, Seattle.

Stenseth, N. C., Jorde, P. E., Chan, K. S., Hansen, E., Knutsen, H., André, C., Skogen, M. D., et al. 2006. Ecological and genetic impact of Atlantic cod larval drift in the Skagerrak. Proceedings of the Royal Society Series B - Biological Sciences, 273: 1085-1092.

Stigebrandt, A. 1983. A model for the exchange of water and salt between Baltic and the Skagerrak. Journal of Physical Oceanography, 13: 411-427.

Svedäng, H., André, C., Jonsson, P., Elfman, M., and Limburg, K. E. 2010a. Migratory behaviour and otolith chemistry suggest fine-scale sub-population structure within a genetically homogenous Atlantic Cod population. Environmental Biology of Fish, 89: 383-397.

Svedäng, H., Righton, D., and Jonsson, P. 2007. Migratory behaviour of Atlantic cod Gadus morhua: natal homing is the prime stockseparating mechanism. Marine Ecology Progress Series, 345: 1-12.

Svedäng, H., Stål, J., Sterner, T., and Cardinale, M. 2010b. Consequences of subpopulation structure on fisheries management: Cod (Gadus morhua) in the Kattegat and Öresund (North Sea). Reviews in Fisheries Science, 18: 139-150.

Svedäng, H., and Svenson, A. 2006. Cod Gadus morhua L. populations as behavioural units: inference from time series on juvenile abundance in the eastern Skagerrak. Journal of Fish Biology, 69 (Suppl. C): $151-164$.

Westerberg, H. 1994. The transport of cod eggs and larvae through Öresund. ICES Document CM 1994/Q:4. 